Journal of Computer Science 3 (3): 149-153, 2007

ISSN 1549-3636

(C) 2007 Science Publications

\title{
Computer Aided Transient Stability Analysis
}

\author{
Nihad M. Al-Rawi, Afaneen Anwar and Ahmed Muhsin Abdul-Majeed \\ Department of Electric and Electronics Engineering \\ Technology University of Science and Technology, Baghdad, Iraq
}

\begin{abstract}
A program for handling and improving the transient stability of the Iraqi Super Grid electrical network was developed. The idea was demonstrated by applying it to the outages of the main generating units. The methodology was built upon a state of increasing power transfer through the healthy portion of network during disturbances. There were three parts concerned; the first part was the developing of the load flow program using fast decoupled method and the transient stability program using Modified Euler's method in the step by step solution, the second part was the engagement between the two programs, the third part was the application of the new program on the Iraqi supper grid network $(400 \mathrm{kV})$.
\end{abstract}

Keywords: Power flow, transient stability, Modified Euler's method, Iraqi supper grid network

\section{INTRODUCTION}

Due to increased power transactions between various power systems and due to continuing postponement of transmission reinforcements, power systems are being operated closer to their lower secure limits. This has exacerbated the traditional conflict between the two major objectives of power system operation, economics and security ${ }^{[1]}$.

Several methods for off line transient stability analysis are under research and development. They contain efficient step-by-step integration of the differential equations, direct method of stability analysis, pattern recognition techniques, expert systems and neural networks. In multi-machine stability studies, the only method that gives satisfactory results is step by step integration method. The step by step time simulation is a conventional method, which is the most reliable one. It gives an accurate result and can handle the complicated system models. The step by step integration method has the advantage that voltages, currents and apparent powers at various buses could be monitored as a function of time during the disturbances.

Among many stability analysis methods, the modified Euler's method is gaining more popularity because of its simplicity and high accuracy. Modified Euler's method is a method that is able to determine stability with explicitly integrating differential equations describing the post-fault system.

The fast decoupled load flow solution requires more iterations than the Newton-Raphson method, but needs considerably less time per iteration and a load flow solution is obtained very rapidly. The storage requirements are about fifty percent less than that of Newton- Raphson. This technique is very useful in contingency analysis where numerous outages are to be simulated or a load flow solution is required ${ }^{[2-4]}$.

The fast-decoupled load flow method is getting more popularity as a result of its simplicity, high speed and low memory requirement. Therefore it was concerned in this work.

\section{The developing of the load flow and the transient stability programs}

The load flow program: The most important mathematical operation in power system analysis is the investigation of load-flow study, which is concerned with the determination of state (variables voltage, current, power and power factor) at a various point of power network. Load flow studies are essential for all power system problems and it is not a simple task. No direct solution can be found to a load flow because of the nature of the equations and ever increasing complexity of power systems ${ }^{[5]}$.

There are many powerful methods for load flow study, but the fast decoupled load flow method has been accepted in recent years by utility industry as the best approach to obtain the power flow solutions. This method is used in system planning, operational planning and operational control due to its low memory requirements, speed and very good convergence characteristics for practical problems.

In this work, a load flow program was developed using the fast decoupled method as shown in Fig. 1.

Corresponding Author: Nihad M. Al-Rawi, Department of Electric and Electronics Engineering, Technology University of Science and Technology, Baghdad, Iraq, Tel: 00-964-7901721082, E-mail: najem20042003@yahoo.com 
The transient stability program: The simplest model used in the transient stability studies is commonly referred to as classical model. The classical model is used to study the transient stability of a power system for a period of time during which the dynamic behavior

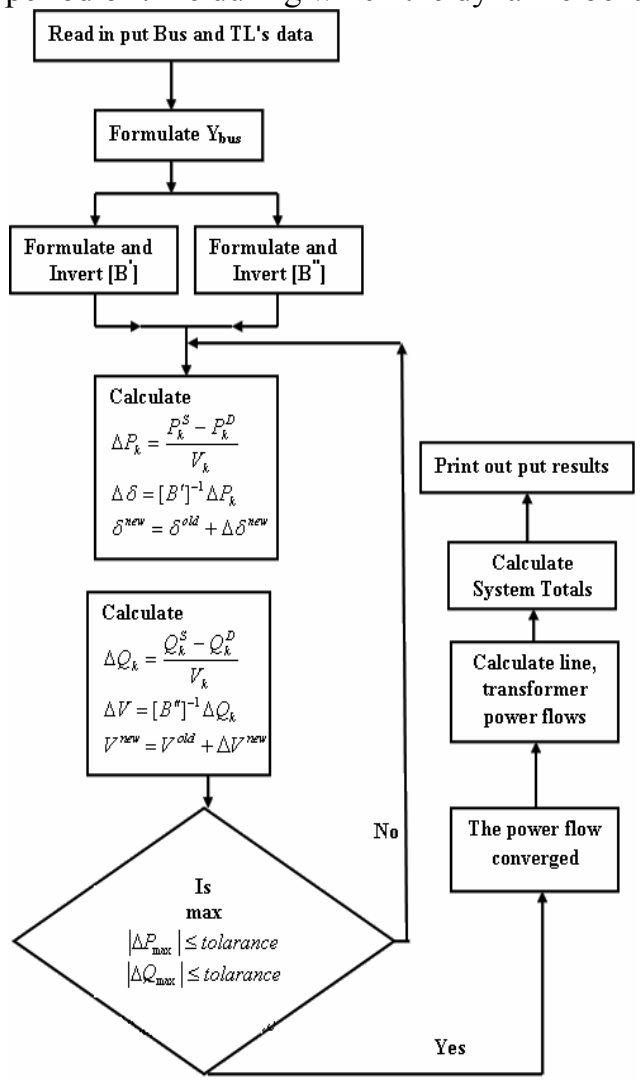

Fig. 1: The flow chart for a fast decoupled power flow program

of the system is dependent largely on the stored energy in the rotating inertias. It's the simplest model and requires a minimum amount of data ${ }^{[6-10]}$.

In this work, a Modified Euler's method is used. The flow chart of the program is shown in Fig. 2.

The engagement between the two programs: The cost of losing synchronous operation through a transient instability is extremely high in modern power systems. Consequently, combining the load flow program with a transient stability program is necessary in order to avoid the problem. The common key between the two programs is the number of bus-bars. The flow chart of the combination process is shown in Fig. 3. This program performs the task of transient stability study when machines are represented in classical model.

The flow chart shown represents the main program which calls different subroutines; such a structure which permits the removal and addition of system components. The transient stability program operates when a fault occurs on the system. If the system is unstable, it gives hint to the load flow program to redistribute the power, i.e., increase the electrical power for generating units in steps chosen. The program will start by reading the data file, converting the transformers to their $\pi$-equivalent, forming the $\mathrm{Y}$ matrix and starting the iterative solving algorithm using fast decoupled method. When the program reaches to a

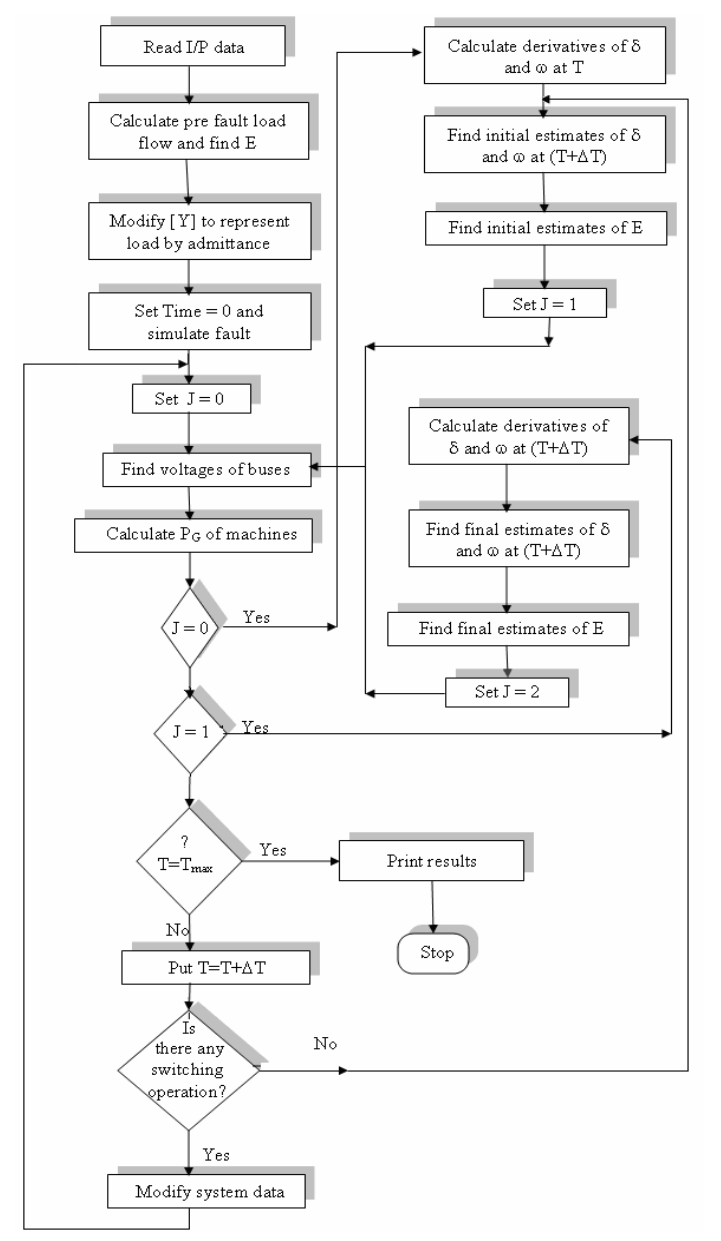

Fig. 2: Flow chart of transient stability study using modified Eulers' method 


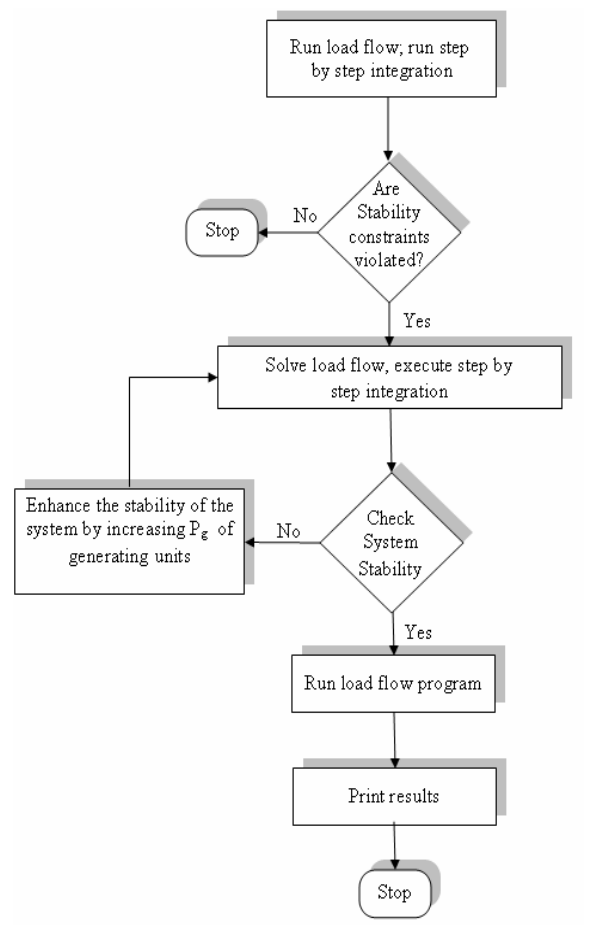

Fig. 3: Flow chart of the new program

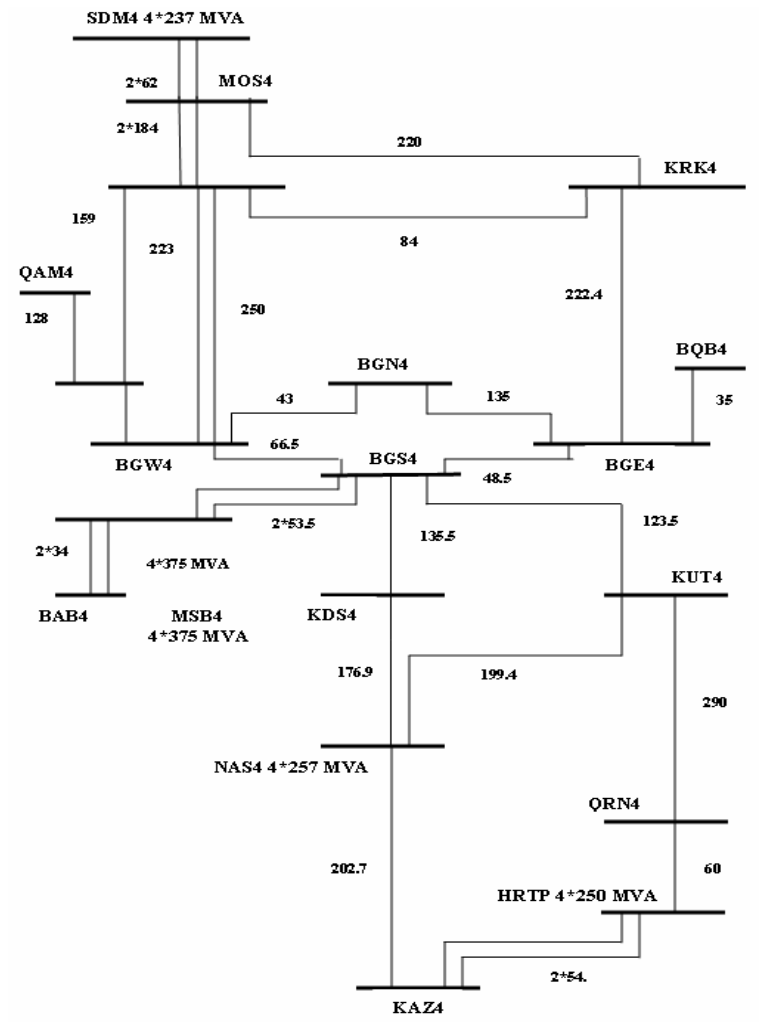

Fig. 4: Configuration of the $400-\mathrm{kV}$ network solution the output information will be fed to the transient stability program again to examine the situation of the network, if the system is stable then the program will be ended and the output files of the transient stability program will be printed if not, the program will raise the generation unit power into the other step and so on until the system reaches the stability situation.

All the three programs were written in MATLAB language using the matlab package version 6 for the load flow program the no. of iteration (8) with 0.0001 tolerances. For the stability program the unit step was 0.005 and fault clearing time is equal to 0.1 second and total solution time is 1.5 second. The execution time for the last program (the combination between the two programs) was 1 minute.

The application of the new program on the Iraqi super grid network: Iraqi electrical network with all its bus bars and transmission lines continue to operate normally and with good efficiency until the events, which began at the 17th -Jun.-1991 and continued till now, after that date a large damages happened to the electrical power system at all its levels : the generation, the transmission and the distribution. This led to a large reduction in the power production of the electrical power. A large number of generating units were separated from the network which causes the unstability of system.

Table 1: $\quad$ System stability and critical clearing times for case (a)

\begin{tabular}{lll}
\hline The separated Unit & The system stability & $\mathrm{T}_{\mathrm{cr}}(\mathrm{sec})$ \\
\hline BAJ4 & Unstable & 0.000781 \\
SDM4 & Stable & 0.684473 \\
HAD4 & Unstable & 0.000781 \\
MSB4 & Stable & 0.509473 \\
NSR4 & Stable & 0.319434 \\
HRT4 & Stable & 0.34541 \\
\hline
\end{tabular}

Table 2: $\quad$ System Stability for case (b)

\begin{tabular}{lll}
\hline The separated Unit & The system stability & $\mathrm{T}_{\text {cr }}(\mathrm{sec})$ \\
\hline BAJ4 & Unstable & 0.000781 \\
SDM4 & Stable & $* * *$ \\
HAD4 & Unstable & 0.000781 \\
MSB4 & Stable & $* * *$ \\
NSR4 & Stable & $* * *$ \\
HRT4 & Stable & $* * *$ \\
\hline
\end{tabular}

The network under consideration represents the Iraqi super grid network which consist of 19 bus-bar and 30 transmission lines, a configuration of this network is shown in Fig. 4, the input data for the load flow and the transient stability programs represent the load and the generation of the 2 nd / jun. $/ 2000$. 
To apply the new program on the network, the Iraqi Grid was analyzed using the transient stability program which was developed in this work to assign the most dangers regions. For this study the total solution time was 1.5 second, the integration step length was 0.005 and the fault clearing time was 0.1 second depending on the time of the first zone of the distance protection used in Iraqi electrical network protection system. Also the faulted line is not returned to the system.

Two types of faults are considered those are:

Case (a): A three phase short circuit near the bus bar which follows the transformer of the generator. This fault will cause the bus bar voltage to be zero. To ensure getting rid of the severe condition, the faulted line is not returned to the system as shown in Table 1.

Case (b): A line switching fault. In this type, fault does not include any short circuit fault, i.e., it only signifies that the circuit breakers of the line removed the line from the system as shown in Table 2 .The mark (***) shows that the system stability not affected by restoring the line.

Enhancement the transient stability of Iraqi grid: Stability is an important constraint in power system operation. A new methodology that reduces the consuming time of the operator to determine a transiently secure operating point is presented. From the obtained results, it is obviously that the network is suffering from serious problems. The outage of the generating bus bars BAJ4 and HAD4, will lead SDM4 bus to swing away from the stability region and will cause the instability of the whole system. While the outages of the rest of the generating buses will not affect the stability of the system.

Table 3: System stability and critical clearing times after the 3rd rise in the generated power of the generating units

\begin{tabular}{lll}
\hline The separated bus-bar & The system stability & $\mathrm{T}_{\mathrm{cr}}(\mathrm{sec})$ \\
\hline BAJ4 & Stable & 0.505371 \\
SDM4 & Stable & 0.665332 \\
HAD4 & Stable & 0.34541 \\
MSB4 & Stable & 0.659863 \\
NSR4 & Stable & 0.435645 \\
HRT4 & Stable & 0.375488 \\
\hline
\end{tabular}

In this study, a program for handling and improving transient stability of Iraqi Super Grid was developed and our idea was demonstrated by applying it to outages of main generating units. The methodology is built upon a state of the increasing power transfer through the healthy portion of network during disturbances, which allows a machine to swing through a larger angle from it original position before it reaches the critical clearing angle. In case (a) and by using the new program, the generating power of the generating units were increased in steps (50 MW in each step) and at each step the transient stability of the system were calculated.

After three steps, the whole system reaches the stability situation in both cases, i.e. case (a) and (b) and the transient stability results of this step are shown in Table 3 .

\section{CONCLUSION}

This study was presented to ensure that transient stability can be maintained by searching an operating point that respects appropriate stability limits. Such a search using power generation increment has to be investigated. From the obtained results one realizes that there are two dangerous regions in the network under consideration, those are the north region (BAJ4 generating unit) and the west region (HAD4 generating unit).

Rising the generation of the generated bus bar in steps (50MW in each step) affects the stability of network. From results obtained by a new program it was clear that after the 3rd step of increasing the generated power led to the stability of the network in all the situations. This increment causes the reduction of the high swing of SDM4.

The new program has the ability to analyze the system by transient stability analysis and then uses the load flow analysis to solve any problem that may arise in the network by increasing the generating power of the generation units. It seems obvious that this new program greatly improves the ability to monitor system stability. It also reveal that the combination between load flow and transient stability programs is suitable for automated computation and helps the operator to take a quick decision to analyze a severe fault in the grid and to give a solution of the problem in one package.

\section{REFERENCES}

1. Anwar, A., 2005. Implementation of geographic information system in transient stability assessment. Ph. D. Thesis. University of Technology, Baghdad, Iraq. 
2. Saadat, H., 1999. Power System Analysis. Mc Graw-Hill.

3. Gubta, B., 1996 .Power System Analysis and Design. 2nd Edn., Wheeler Pub.

4. Sauer, P. and M. Pai, 1998. Power System Dynamics and Stability. Prentice-Hill, New Jersey USA.

5. Humpage, W.D., 1998. Power System Load Flow Analysis.

6. Pai, M., 1981. Power System Stability. North Holland Publishing Co.
7. Pai, M., 1979. Computer Techniques in Power System Analysis. Tata-Mc Graw-Hill Ed.

8. Kirshnaparandhama, 1980. Fast power flow solution by the method of reduction and restoration. IEEE Trans. PAS., 127: 2.

9. Mc Claymont, K., 1986. Experience with high speed rectifier excitation system. IEEE Tran. PAS., Vol. 87.

10. Weedy, B. and B. Cory, 1998. Electrical Power System. John Wiley \& Sons, 4th Edn. 